\title{
Effect of Alkali-Silica Reaction on the Shear Strength of Reinforced Concrete Structural Members. A Numerical and Statistical Study
}

\author{
Victor E. Saouma ${ }^{\mathrm{a}}$, Mohammad Amin Hariri-Ardebilia ${ }^{\mathrm{a}}$, Yann Le Pape ${ }^{\mathrm{b}}$, \\ Rajagopalan Balaji ${ }^{\mathrm{a}}$ \\ ${ }^{a}$ Department of Civil Engineering, University of Colorado, Boulder, CO 80305, USA \\ ${ }^{b}$ Oak Ridge National Laboratory, One Bethel Valley Road, Oak Ridge, TN 37831, USA
}

\begin{abstract}
The residual structural shear resistance of concrete members without shear reinforcement and subject to alkali-aggregate reaction (ASR) is investigated by finite element analysis. A parametric numerical study of 648 analyses considering various structural members' geometries, boundary conditions, ASR-induced losses of materials properties, ASR expansions and reinforcement ratios is conducted. As a result of competitive mechanisms (e.g., ASR-induced prestressing caused by the longitudinal reinforcement) and loss of concrete materials properties, important scatter in terms of gain or loss of shear strength is observed: about $50 \%$ of the studied configurations lead to a degradation of structural performance. The range of variation in terms of post-ASR shear resistance is extremely scattered, in particular, when ASR results in out-of-plane expansion only. Influencing factors are derived by two methods: (i) visual inspection of boxplots and probability distributions, and (ii) information criteria within multiple-linear regression analysis.
\end{abstract}

Keywords: concrete, alkali-silica reaction, shear strength, degradation, finite element, containment building

\section{Introduction}

Whereas alkali-silica reaction (ASR) has been reported in numerous hydroelectric dams, only recently has there been evidence of such occurrences in nuclear power plants (NPPs): in Japan, Ikata No. 1, Shikoku Electric Power (Takatura et al., 2005; Shimizu et al., 2005); in Canada, Gentilly 2 (Tcherner and Aziz, 2009; Sanborn, 2015); and in the United States, Seabrook (ML121160422, 2012; Haberman, 2013), for which the US Nuclear Regulatory

*Corresponding author: lepapeym@ornl.gov (Y. Le Pape)

Preprint submitted to Nuclear Engineering and Design

October 6, 2016

(C) 2016. This manuscript version is made available under the Elsevier user license http://www.elsevier.com/open-access/userlicense/1.0/ 
Commission (NRC) issued Information Notice (IN) 2011-20, "Concrete Degradation by Alkali Silica Reaction," on November 18, 2011. Considering that US commercial reactors in operation have reached the age when ASR degradation could be visually detected and that numerous nonnuclear infrastructures (transportation, energy production) have already experienced ASR in a large majority of the States (e.g., a US Department of Transportation (DOT) survey reported by Touma (2000)), the susceptibility and significance of ASR for nuclear concrete structures must be addressed in the perspective of license renewal and long-term operation beyond 60 years. Yet, ASR has seldom, if ever, been reported in the open literature in connection with its significance for Safety Class $\mathrm{I}^{1}$ nuclear concrete structural components, e.g., the concrete biological shield, the concrete containment building (CCB) and the fuel handling building.

The evaluation of the structural significance of ASR-affected concrete structures in NPP presents some specificities in terms of design and exposure conditions, that limits a direct interpretation based on the analysis of transportation infrastructures or concrete dams, though the methodological pathways could be similar to a large extent.

The interaction of ASR with concrete shear strength is of primary interest. At the material level, the concrete degrades and undoubtedly its shear resistance is decreased. On the other hand, at the structural level, ASR induces additional compressive stresses, similar to a prestressing effect, which increase the shear resistance of the structural component. An illustration of this effect is given by the analysis of the simple Mohr-Coulomb equation: $\tau=c+\sigma \tan \phi$. For a cohesion of $c=3 \mathrm{MPa}$ and an internal friction angle of $\phi=40^{\circ}$, then for a compressive stress $\sigma$ of 0,3 and $5 \mathrm{MPa}$, the resulting shear strength would be 3.0, 5.5 and 7.2 MPa respectively. Furthermore, the ASR expansion is likely to reduce the crack opening due to shear, hence additional aggregate interlock is present (Blight and Alexander, 2008).

The effects of ASR on structural members' resistance are apparently contradictory. When shear reinforcement is present, the expansion confinement results in a prestressing of concrete that contributes to an increasing shear capacity, e.g., (Giannini et al., 2013), or an absence of significant change (Fan and Hanson, 1998). However, it was observed that shear failure may shift from a truss mechanism to a arch mechanism (Wang and Morikawa, 2012). Also, excessive ASR-induced self-prestressing may cause reinforcement yielding and failure (Nakamura et al., 2008; Miyagawa, 2013). Of particular concern is the case of beams, or slabs, in absence of shear reinforcement (Bach et al., 1993; den Uijl and Kaptijn, 2003; Schmidt et al., 2014). den Uijl and Kaptijn (2002, 2003) tested the shear capacity of six beams sawn from two flat-slab bridges suffering from ASR in the Netherlands. The failure mode was of the shear-tension type, whereas flexural-shear failure would have been expected if no ASR was present. The shear failure capacity was $25 \%$ lower than the expected theoretical

\footnotetext{
${ }^{1}$ Class I referring to leak tightness, this study does not address the impact of ASR-induced cracking on possible gas diffusion.
} 
resisting capacity in absence of ASR. In situ shear tests on a cantilever bridge deck conducted by Schmidt et al. (2014) in Denmark showed significant loss of bearing capacity (i.e., smaller shear failure force) in the severely ASR-affected area. Finally, effect of shear span ratios on the failure modes of ASR-affected beams (truss or arch like) has not been investigated to the best of the authors' knowledge.

The absence of shear reinforcement (i.e., in thickness) permitted by ACI 349 (Code Requirements for Nuclear Safety-Related Concrete Structures) is common in nuclear concrete structures, resulting in a lack of confinement that primarily imposes out-of-plane ASR expansion. Hence, the residual (i.e., post-ASR) shear-bearing capacity relies in large part on the concrete bulk shear resistance. The residual shear capacity (i.e., reduced shear-carrying capacity following an accidental design scenario, such as a seismic excitation) of ASR-affected Safety Class I structural components is expected to depend on two competitive mechanisms: (1) the extent of material damage, i.e., microcracking, potentially facilitating their coalescence into a macrocrack and (2) the relative in-plane compressive prestressing induced by some level of structural confinement and the orientations of the reinforcement, potentially increasing the shear capacity. This question remains unresolved, and further investigation is needed to determine the potential impact of ASR on the structural resistance of nuclear structures. This article presents an extensive parametric numerical study providing novel insight on the effect of ASR on the shear capacity of reinforced concrete (RC) members without shear reinforcement.

\section{Model and methodology}

\subsection{ASR Constitutive Law}

The theoretical underpinning of the model used in this paper has been presented by the authors separately, Saouma and Perotti (2006a). It will be briefly reviewed. The ASR expansion is considered to be a volumetric one, whose rate is given by the function

$$
\dot{\varepsilon}_{V}^{A S R}(t)=\left.\Gamma_{t}\left(f_{t}^{\prime}\left|w_{c}, \sigma_{I}\right| C O D_{\max }\right) \Gamma_{c}\left(\bar{\sigma}, f_{c}^{\prime}\right) g(h) \dot{\xi}(t, \theta) \varepsilon^{\infty}\right|_{\theta=\theta_{0}}
$$

where $\varepsilon^{\infty}$ is the final volumetric expansion as determined from laboratory tests at temperature $\theta_{0} .0 \leq \Gamma_{t} \leq 1$ is a parameter that reduces the expansion in the presence of large tensile stresses (macrocracks absorbing the gel), $f_{t}^{\prime}$ the tensile strength, and $\sigma_{I}$ the major (tensile) principal stress. Similarly, $0 \leq \Gamma_{c} \leq 1$ is a parameter that accounts for the absorption of the gel due to compressioninduced stresses, and $\bar{\sigma}$ and $f_{c}^{\prime}$ are the hydrostatic stress and the compressive strength of the concrete. $0 \leq f(h) \leq 1$ is a function of the humidity (set to zero if the humidity is below $80 \%$ ), and $\dot{\xi}(t, \theta)$ is the kinetics law given by

$$
\xi(t, \theta)=\frac{1-e^{-\frac{t}{\tau_{c}(\theta)}}}{1+e^{-\frac{\left(t-\tau_{l}(\theta)\right)}{\tau_{c}(\theta)}}}
$$


where $\tau_{l}$ and $\tau_{c}$ are the latency and characteristic times respectively. The first corresponds to the inflexion point, and the second is defined in terms of the intersection of the tangent at $\tau_{L}$ with the asymptotic unit value of $\xi$, Figure 1.

The latency time $\tau_{l}$ and characteristic times $\tau_{c}$ are given by

$$
\begin{aligned}
\tau_{l}(\theta) & =\tau_{l}\left(\theta_{0}\right) \exp \left[U_{l}\left(\frac{1}{\theta}-\frac{1}{\theta_{0}}\right)\right] \\
\tau_{c}(\theta) & =\tau_{c}\left(\theta_{0}\right) \exp \left[U_{c}\left(\frac{1}{\theta}-\frac{1}{\theta_{0}}\right)\right]
\end{aligned}
$$

expressed in terms of the absolute temperature $\left(\theta^{\circ} K=273+T^{\circ} C\right)$ and the corresponding activation energies. $U_{l}$ and $U_{c}$ are the activation energies' minimum energy required to trigger the reaction for the latency and characteristic times respectively.

Once the volumetric ASR strain is determined, it is decomposed into a tensorial strain in accordance with the three weight factors associated with the principal stresses (Saouma and Perotti, 2006a).

Note that the material follows a time-dependent deterioration as

$$
\begin{aligned}
& \frac{E(t, \theta)}{E_{0}}=1-\left(1-\beta_{E}\right) \xi(t, \theta) \\
& \frac{f_{t}^{\prime}(t, \theta)}{f_{t 0}^{\prime}}=1-\left(1-\beta_{f}\right) \xi(t, \theta)
\end{aligned}
$$

where $E_{0}$ and $f_{t 0}^{\prime}$ are the original elastic modulus and tensile strength, and $\beta_{E}$ and $\beta_{f}$ are the corresponding residual fractional values when $\varepsilon_{A S R}$ tends to $\varepsilon_{A S R}^{\infty}$.

\subsection{Model Selection}

A representation of the analyzed structural components in regard to actual CCB geometry is illustrated in Figure 2. On the left side are sketched the beam, the truncated beam and the panel under investigation. Because of the large curvature radius of the CCB (about 20-25 m), reinforcements are considered straight for the sake of simplicity.

\subsection{Boundary Conditions}

As stated earlier, two sets of boundary conditions are considered: (1) those applicable during ASR expansion (simulation increments 1-73) and (2) those applicable during the application of external shear force (simulation increments 74-174). The former is to capture potential ASR strain realignments caused by external constraints (Multon, 2004) as implemented in the author's model (Saouma and Perotti, 2006b).

The choice of geometries (beam, truncated beam and panel) and boundary conditions (unrestrained, restrained and fully restrained) reflects an attempt to model gradually increasing structural restraints, as existing in actual Safety Class I concrete structures due to the presence of adjacent or internal structures, as well as other connecting structural members (basemat, floors and walls). 
Note that Safety Class I structures are not limited to the containment buildings: the International Agency for Atomic Energy (IAEA Specific Safety Guide No. SSG-30) labels Safety Class I as "any structures, systems and components whose failure would lead to consequences of 'high severity," for example, primary containment, basemat, internal structures, auxiliary building, diesel generator building, and part of the turbine building.

The boundary conditions are presented schematically in Figure 3. Details are also provided in Table 1. It should be noted that for both "restrained" and "fully restrained" cases, there is a lateral confinement for ASR expansion; however, the difference lies in the absence or presence of a vertical one.

\subsection{Dimensions}

Two different depths are considered: 24 and 48 in. (0.61 $\mathrm{m}$ and $1.22 \mathrm{~m}$ ) in an attempt to cover the range of Safety Class I reinforced concrete walls in NPPs. In particular, the thickness of the CCB is typically greater than $3 \mathrm{ft}(0.91 \mathrm{~m})$. Actual dimensions of the three structural members under consideration in this study are shown in Figure 4 with reference to Table 2.

\subsection{Finite Element Meshes and Analyses}

The finite element meshes were generated with Kumo (Saouma, 2009). A sample finite element mesh with detailed reinforcements is shown in Figure 5 with the indication of the number of nodes and elements shown (same numbers for 24 and $48 \mathrm{in.)}$ in Table 3. In all cases, 3D eight-node linear continuum elements are used. Meshes were "optimized" so as to guarantee sufficient refinement while maintaining computational "affordability." This was achieved by testing various meshes and convergence criteria, and comparing displacements. The mesh is refined at the location of applied load and also support (for the beam and truncated beam models) to properly capture the load transfer mechanism and also possible cracking at these locations.

Two orthogonal sets of reinforcements are used at the top and bottom of the concrete specimen. The longitudinal and transverse ones correspond to the vertical and hoop reinforcement in the nuclear containment structure, Figure 2. Full bond is assumed, and reinforcement is modeled by properly altering the stiffness matrix of crossed finite elements (which greatly facilitates mesh preparation) using an elasto-plastic constitutive model.

All analyses were performed with the Merlin finite element code (Saouma et al., 2010) using the Secant Newton algorithm and setting the maximum number of iterations to 300. The convergence criterion for both energy (ratio of the absolute values of the external work done by the applied incremental loads and the residual loads for the current increment) and displacements (ratio of the Euclidean norms of the iterative displacement correction and incremental displacement vectors) was set to 0.01 . Though far from ideal, these analyses were compared with others having tighter convergence criteria and though oscillatory behaviors were observed in the post-shear failure, i.e., post-peak, they were kept in the interest of computability. A rotating crack model was used (Rots, 1991). 
Four workstations are used to perform the analyses (Intel Xenon 3.6 GHz, RAM 8.00 GB). Each simulation had a computational cost between 6 and 60 hours. Higher computational time is a result of unfavorable combinations of the input random variables (e.g., ASR expansion, reinforcement ratio, strength reduction coefficient). These input parameters are explained in Sec. 4.

In all ASR simulations followed by a shear test (ASR+Shear), ASR was applied through the first 73 increments, while incremental shear was applied from increment 74 through 174 . At the end of the ASR expansion, the results were visualized to assess whether full expansion was reached.

Finally, it should be noted that a good indicator for discarding diverging results is the out-of-plane displacements. A threshold value of $5 \mathrm{~mm}$ (based on examination of finite element analyses results) was set.

\subsection{Variables}

Two set of meshes are generated (Table 4):

ASR + Shear cases for which seven variables were included in the study, see Table 4 . Thus, for each of the three geometries a total of $(3 \times 2 \times 3 \times 3 \times 2 \times 2)$ 216 meshes were generated, i.e., 648 total.

Reference cases with no ASR modeling. For each of the three geometries a total of $(3 \times 2 \times 3) 18$ meshes were generated (or 54 total).

\section{Material Properties}

The constant material properties for the concrete nonlinear model described previously (Saouma and Perotti, 2006b) are given in Table 5. Details on the constitutive model are provided in Appendix 2.1. These values were adopted as representative of an ordinary structural concrete with a compressive strength of 4,500 psi (31 MPa). This value corresponds to a standard design requirement for structural concrete in NPPs in the 1970s and 1980s, although higher values could have been obtained in practice (Granger, 1995). Table 6 provides the characteristics of the ASR model. The maximum ASR expansion, in unrestrained conditions, is taken equal to $0.1 \%, 0.2 \%$ and $0.3 \%$ to increase the severity of the induced damage before applying the shear loading. The residual elastic modulus and tensile strength resulting form ASR degradation are assumed to be either $70 \%$ or $90 \%$. The mechanical constitutive model for the reinforcing steel bars is assumed elasto-plastic. The corresponding properties are given in Table 7. Three flexural reinforcement ratios (defined for each of the two layers) are considered: $0.2 \%, 0.5 \%$ and $1 \%$.

\section{Deterministic simulation}

A set of 648 cases were simulated corresponding to different geometries, conditions or material properties: 
A Geometry (B-TB-P): for beam, truncated beam or panel;

B Depth (2-4): for 24" (61 cm) and 48" (1.22 m);

C Boundary conditions ( $\mathrm{U}-\mathrm{R}-\mathrm{FR}$ ): for unrestrained, restrained and fully restrained;

D Final ASR expansion, $\varepsilon^{\infty},(1-2-3)$ : for $0.1 \%, 0.2 \%$ and $0.3 \%$;

E Reinforcement ratio, $\rho,(2-5-10)$ : for $0.2 \%, 0.5 \%$ and $1 \%$;

F Residual Young modulus relative coefficient, $\beta_{E}$, (7-9): for $70 \%$ and $90 \%$;

G Residual tensile strength relative coefficient, $\beta_{f t},(7-9)$ : for $70 \%$ and $90 \%$.

Each simulation corresponds to the successive modeling of (1) the ASR development and induced damage (pre-shear-testing) and (2) the residual shear test. The results of the residual shear test are compared with the reference shear test obtained on the corresponding pristine structural element. For each simulation, a set of scalar outputs are calculated: variation of the shear capacity, variation of stiffness, ASR dimensional change in the unreinforced direction of the structural element, and median and maximum stresses in the reinforcement bars in both directions. With rare exception, the general shear force-displacement curve exhibits a shear capacity peak followed by a sudden drop. Increasing post-peak displacements leads to varied behaviors including hardening or softening.

Note that the ultimate shear capacity is the absolute peak of the curve, whereas the yield value is defined as shear deviating by $15 \%$ from the elastic stiffness (Figure 6). Whereas this definition of yield shear may appear to be arbitrary, it was the most adequate convention for the automatic processing of hundreds of simulation results.

A total of 648 2D plots, similar to those presented in Figure 7, are generated for each individual analysis. In the 2D plots, the top-left portion shows the shear behavior in term of shear force vs the shear displacement before ("only shear," solid red line) and after ASR ("ASR+shear," solid blue line). The variations of shear strength and stiffness are also provided in the legend. The top-right portion shows the progression of the ASR out-of-plane expansion as a function of the computational increments. Full expansion at the end of the $73^{\text {rd }}$ increment is expected.

The lower plots correspond to the representation of the stress distribution in the longitudinal and transverse reinforcing bar using box-and-whisker diagrams, also known as boxplots. Note that boxplots are a standardized way of displaying the distribution of data based on five numbers. In this investigation $\mathrm{R}$ Core Team (2015) was used, and top and bottom horizontal lines correspond to the third and first quartiles (Q3 and Q1), respectively. The height of the box is the interquartile range (IQR). The line in the middle is the median (or the second quartile, Q2). The top whisker denotes the maximum value or "Q3 $+1.5 \times$ IQR," whichever is smaller. The bottom whisker denotes either the minimum value or "Q1 - 1.5 × IQR," whichever is larger. Any data point beyond the top and bottom whisker is referred to as an outlier. 


\section{Probabilistic analysis}

Though we began by looking at individual results, it quickly became clear that such an effort was not only monumental but could easily lead to erroneous interpretation.

As such, it was rapidly concluded that a thorough statistical analysis of results was the only practical approach. A statistical analysis was performed using the $\mathrm{R}$ package ( $\mathrm{R}$ Core Team, 2015). The results of the analysis are reported in the following sections.

\subsection{ASR Effects on Material and Structures}

The nonlinear numerical model used in Merlin is a fracture-plastic based on the work (and implemented) by Červenka and Papanikolaou (2008). It combines constitutive models for tensile (fracturing) and compressive (plastic) behavior. The fracture model is based on the classical orthotropic smeared crack formulation and crack band model. It employs Rankine failure criterion, exponential (or user-defined) softening, and it can be used as a rotating or fixed-crack model. The hardening/softening plasticity model is based on the Menétrey and Willam (1995) failure surface. Both models use a return mapping algorithm for the integration of constitutive equations. The model can be used to simulate concrete cracking, crushing under high confinement, and crack closure due to crushing in other material directions. Dowel effects are not modeled, while interlocking effects are implicitly accounted for. Hence, the model does take into account the confining effect and will result in higher shear strength.

As such, differentiation will be made between results showing positive or negative shear strength changes. This task is simply achieved by properly filtering the $\mathrm{R}$ dataset in terms of the shear strength change. Among the full set of 648 analyses, $53 \%$ resulted in overall shear strength decrease, and $47 \%$ in increase.

\subsection{Statistical Analysis}

In this second part of statistics-based data interpretation, we seek to develop a model for shear strength change - not to gain a mathematical model, per se, that could be plotted (use of unordered categorical variables), but rather to identify the most relevant parameters among those used. In this exercise, each of the 18 sub-variables in Table 8 will be separately considered. The employed multiple linear regression analysis is described in some details in Appendix A.

Three fitting models are considered:

1. Full data set:

- General model: considering all variables;

- Best model based on Akaike Information Criterion (AIC): filters the final sub-variables based on AIC;

- Best model based on Bayesian Information Criterion (BIC): filters the final sub-variables based on BIC. 
2. Increased shear strength change data set:

- General model;

- Best model based on AIC;

- Best model based on BIC.

3. Decreased shear strength change data set:

- General model;

- Best model based on AIC;

- Best model based on BIC.

\section{Joint statistical analysis of the full dataset}

\subsection{Boxplots and Histograms}

Before any statistical model is developed to assess the influence of the studied parameters, all results are presented as boxplots and histograms. However, rather than dealing with the seven classes of main variables, it was deemed necessary to express the model in terms of each one of their possible values, see Table 8 . It should be noted that the $\mathrm{R}$ code internally uses normalized/integer values for each of the 18 sub-variables. Boxplots for each of the 18 sub-variables are presented in the next section. For each specific case, it is assumed to be a function of that specific sub-variable and the coupled effect of all 17 others.

The analysis separates the simulations for which the shear strength increases from those showing a decrease of shear strength.

\subsubsection{Shear Strength Increase}

Figure 8 presents the boxplots relative to increasing shear strength. The following observations can be made (trends corresponding to average values primarily):

- The impact of the nature of the structural elements, (B) and (TB) geometries, on the increase in shear strength is nearly identical; however, $\mathrm{P}$ geometry leads to increased variability, Fig. 8(a).

- The 24 in. thick specimens (smaller dimensions) have a slightly larger shear strength increase, possibly attributable to a size effect, than the larger specimens, Fig. 8(b).

- Restrained boundary conditions (R) appear to significantly increase the shear strength although important scatter is found, Fig. 8(c).

- Greater reinforcement (higher $\rho$ ) leads to greater increase in shear strength, Fig. 8(e).

- Higher reduction in $\beta_{E}$ results in higher reduction in stiffness, Fig. 8(f). 
- Similarly, a larger decrease in $\beta_{f t}$ results in a smaller increase in strength, Fig. 8(g).

In all of the above, factors of influence are what one may anticipate, although their quantitative impact may be judged quite limited.

\subsubsection{Shear Strength Decrease (Negative Set)}

Following a similar approach, this subsection seeks to understand the underlying reasons for shear strength decrease at the structural level due to each of the 18 subvariables. Again, each boxplot is an indicator of the impact of a given subvariable in terms of all 17 others and its impact on shear strength decrease.

Figure 9 shows the boxplots for the shear strength decrease, and the following observations can be made:

- $(\mathrm{P})$ geometry results in higher decreases than (B) or (TB) geometries, $9(\mathrm{a})$.

- Greater depth (48 in.) results in higher shear strength reduction than 24 in. components, 9(b). Also, the variation in response for the larger structural members is smaller.

- The largest shear strength decrease occurs for the restrained (R) situation for which the out-of-plane expansion is uniform in the vertical direction and constrained in the lateral hoop direction only. It is noteworthy that this configuration is quite representative of large structural walls, 9(c). Furthermore, the variations corresponding to the $(\mathrm{R})$ boundary conditions are much higher than when associated with the (U) and (FR) BCs. Fifty percent of the strength reduction cases associated with the $(\mathrm{R}) \mathrm{BCs}$ fall in the range of $[20 \% ; 95 \%]$ (higher reduction). Corresponding ranges for $(\mathrm{U})$ and $(\mathrm{FR}) \mathrm{BCs}$ are $[7 \% ; 27 \%]$ and $[2 \% ; 7 \%]$, respectively.

- Increasing ASR expansion, $\epsilon^{A S R}$, increases the mean value of the strength reduction in the models. This is consistent with intuition, 9(d). In addition, for the case with $\epsilon^{A S R}=0.3 \%$ (the largest expansion considered in this study), the structural responses are more scattered than for lower expansions. In particular, the number of cases with strength reduction of nearly $100 \%$ is significantly higher.

- The effect of reinforcement ratio is rather puzzling: strength reductions are closely independent of the value of the reinforcement ratio, i.e., $\rho$ may not have a determining effect in these analyses since steel may not have yielded, $9(\mathrm{e})$.

- $\beta_{E}$ and $\beta_{f t}$ do not seem to have important impact on the results. This is understandable as the zone in shear is largely dominated by compression. Their impact would be greater in assessing the out-of-plane displacements, $9(\mathrm{f})$ and $9(\mathrm{~g})$. 


\subsubsection{Model Fitting and Preliminary Conclusions}

As mentioned earlier, the effect of ASR on the shear strength of concrete structural components is a complex interplay between two effects: (1) material degradation, where undoubtedly ASR reduces the tensile strength of the concrete and is very likely to affect the shear strength of concrete, and (2) structural effect, where steel constrains the concrete expansion, thus putting the later in compression, which will de facto increase its shear resistance. Those effects coalesce in the 648 analyses performed, and corresponding interpretation was provided through the statistical approach previously presented. Table 9 summarizes the three sets of results in terms of relevance of the 18 studied sub-variables. For each dataset and statistical method, the top seven most relevant sub-variables are ranked ( 1 being the most prominent variable). The most important preliminary conclusions are:

1. The boundary conditions (R), i.e., "restrained," are the primary cause of shear strength increase or decrease. Note that this effect is masked when the whole results dataset is considered, i.e., when increasing and decreasing shear strengths are combined in the analysis.

2. For shear strength increase the second most important parameter is $\rho=$ $1 \%$, i.e., the highest reinforcement ratio considered.

3. For shear strength decrease, the second most important parameter is the maximum ASR expansion $\varepsilon=0.3 \%$.

\section{Statistical analysis of restrained boundary $(R)$ conditions scenario}

The preponderant role played by the $(\mathrm{R})$ boundary condition was just demonstrated. To better focus on that scenario, a more refined investigation of this specific case and its 216 analyses is performed by filtering out the (FR) and (U) BCs cases.

\subsection{BoxPlots}

\subsubsection{Shear Strength Increase (Positive Set)}

Figure 10 shows the boxplots for the shear strength increase only for the restrained $\mathrm{BCs}(\mathrm{R})$ models. It can be noted that:

- The impact of (B) geometry on shear strength increase is more important than for (TB) and (P) geometries. Variability associated with the (TB) geometry is higher than for other geometries, 10(a).

- The 24 in. specimens (smaller dimensions) have a slightly larger variability in shear strength increase (size effect?) than the larger specimens, 10(b).

- Lower reinforcement ratio leads to larger shear strength increase, 10(d).

- Higher ASR-induced reduction of Young's modulus $\left(\beta_{E}\right)$ results in smaller shear strength increase, 10(e). 
- Similarly, a larger decrease in the ASR-induced loss of strength $\left(\beta_{f t}\right)$ results in smaller increase in shear strength, 10(f).

Figure 11(a) shows the histogram of the reduced dataset relative to shear strength increase (due to ASR). Figure 11(b) shows the probability distribution function (PDF) of this data set. The dataset does not appear to follow a specific standard distribution. About $80 \%$ of the data falls in the range [0; 50\%] of increase in strength.

\subsubsection{Shear Strength Decrease (Negative Set)}

As previously, this subsection seeks to understand the underlying reasons for shear strength decrease at the structural level due to each of the 15 sub-variables. Again, each boxplot is an indicator of the impact of a given sub-variable in terms of all 14 others and its impact on shear strength decrease.

Figure 12 shows the boxplots for the shear strength decrease and only the restrained model. The following observations can be made:

- (P) geometry results in higher decreases than (B) and (TB) geometries, 12(a). However, the variability of the data is nearly identical.

- Greater depth (48 in.) results in greater shear strength reduction than for $24 \mathrm{in}$. members, 12(b). The variation in output strength is nearly identical in both cases.

- Increasing the ASR expansion, $\epsilon^{A S R}$, increases the mean value of the strength reduction in the models, as intuition would suggest, 12(c). Considerably higher variation is observed for the $0.2 \%$ expansion-case.

- The values of $\beta_{E}$ and $\beta_{f t}$ do not seem to have a significant impact on the loss-of-strength distribution. Their impact would be greater while assessing the out-of-plane displacements, $12(\mathrm{e})$ and $12(\mathrm{f})$.

Figure 13(a) shows a histogram of the data set for shear strength decrease. Figure 13(b) displays the probability distribution function (PDF) for this data set. About $20 \%$ of the data falls in the range [-100\%; -90\%], i.e., corresponding to very limited, if any, residual shear capacity.

\subsection{Model Fitting: Increased Shear Strength}

This sub-subsection repeats the statistical analysis previously presented but is limited to positive shear strength change data points (i.e., strength increase) and the restrained model. First, the general model is fitted, followed by the AIC and BIC best-fit models.

\subsubsection{General Model for Increased Shear Strength Data Set}

Table 10 shows the results of linear model fitting based on positive shear strength change data points. Three different techniques are used for fitting the data points: general model, AIC and BIC. These three approaches provide nearly identical results. 
The main factors influencing the gain of shear strength for a structural member exhibiting only out-of-plane expansion, labeled in this study by type-(R) boundary conditions, are (i) higher reinforcement ratios of $0.5 \%$ and $1 \%$; (ii) an ASR-induced residual the tensile strength at $90 \%$ of its initial value; (iii) ASR expansion of $0.2 \%$; and to a lesser extent, (iv) the nature of the structural member, as (P)-member appears also as a factor of importance. The role of ASR expansion on the shear strength increase appears non-monotonic: while the $0.2 \%$-value is a significant factor of influence, the lower expansion value $(0.1 \%)$ does not contribute notably, and the higher expansion value $(0.3 \%)$ contributes more moderately. This tends to support the hypothesis of a potential ambivalent role of ASR on the structural capacity of members without shear reinforcement: ASR in-plane-restrained expansion results in a prestressing effect that enhances the shear resistance of the member, but loss of materials properties affects the shear resistance, i.e., fracture propagation, in the bulk of the structural member. Limited loss of concrete tensile strength (10\%) impacts the structural shear capacity as it helps the transfer of shear force in the bulk of the member. Higher loss (30\%) of the concrete tensile strength does not play a role in potential increase of the structural shear capacity, suggesting that a significant portion of the shear capacity is related to shear stress in concrete that could rapidly vanish with even limited material strength loss. That the panel (P) geometry appears a factor of influence, albeit low, could be related to the failure mechanism for this specific geometry and loading conditions: while the (B) beam and (TB) truncated beam develop flexural behavior accompanying shear, the $(\mathrm{P})$ condition develops primarily shear failure mode.

\subsection{Model Fitting: Negative Shear Strength Change Data Set}

The analysis presented here is limited to the simulation outputs exhibiting decreased shear strengths. Table 11 shows the results of linear model fitting. First, the general model is fitted, followed by the AIC and BIC best-fit models. The important parameters are:

- General model: $\epsilon^{A S R}=0.3 \%, \rho=1 \%$, and member height, 48in. are the most significant sub-variables.

- AIC: The number of contributing subvariables reduces to 5 (compared to the original 9 subvariables). Still $\epsilon^{A S R}=0.3 \%, \rho=1 \%$, and the member height of, 48in. are the most significant sub-variables.

- BIC: The number of contributing sub-variables reduces to 2. $\epsilon^{A S R}=0.3 \%$, and $\epsilon^{A S R}=0.2 \%$ are the most significant sub-variables.

That higher expansions lead to loss of shear strength is somewhat in agreement with intuition, as more damage develops in the bulk of concrete. More surprising is the importance of the reinforcement ratio. Higher reinforcement ratio is susceptible to increasing the ASR-induced prestressing of the structural member. Conversely, lower reinforcement ratios reduce the benefit of ASR-induced prestressing on structural shear capacity. The highest value of 
reinforcement ratio chosen for this particular study is identified by the general and the AIC models as highly significant for the reduction of structural shear capacity is an indication that other combined factors, such as the anisotropic expansion-induced damage, play a significant role regarding the susceptibility of deteriorating the members' shear resistance.

\subsection{Partial Conclusions on the Model Fitting (Level 2)}

The model-fitting analysis that limited the structural members subjected to $(\mathrm{R})$ restrained boundary condition indicates that the impactful variables, i.e., ASR-induced expansion and loss of mechanical properties, reinforcement ratio, and structural member geometry, in terms of structural shear capacity reduction or gain, are not intuitive. The convergent results obtained by the general model, AIC and BIC analysis, suggest that "competitive" mechanisms drive the structural response against shear loading, particularly ASR-induced prestressing against materials properties degradation.

\section{Conclusion}

A parametric numerical study of the residual structural shear capacity of structural members without shear reinforcement and subject to ASR was conducted using finite element analysis. Different sets of parameters were investigated: geometry of the structural members, boundary conditions, ASR-induced loss of materials properties, ASR expansion and reinforcement ratio. Among the full set of 648 analyses, $53 \%$ resulted in overall post-ASR shear strength decrease, and $47 \%$ in an increase. The range of variation in post-ASR shear strength is particularly large.

Statistically speaking (mean and deviation), highest gains of structural shear strength are achieved for greater reinforcement ratio and restrained boundary conditions, while highest losses are observed for the same boundary conditions and higher ASR expansions.

Because the restrained boundary $(\mathrm{R})$ configuration, i.e., causing out-of-plane expansion only, produces large variations of shear resistance and is representative of a nuclear Safety Class I 'large wall,' a subsequent analysis, focusing on that particular case, was performed.

In terms of variation (mean values), it was found that (1) the highest gains of shear resistance are obtained with the lowest reinforcement ratio, (2) multilinear regression and parameter selections analysis show that minimal loss of concrete tensile strength has a significant impact on potential gain in structural resistance, (3) the loss shear capacity amplitude is extremely scattered, and (4) the greater losses appear to result from large ASR expansions and, nonintuitively, high reinforcement ratios.

However, these general trends cannot be generalized to any specific set of configuration as complex interactions appear to occur. In particular, the role of the structural constraint during the development of ASR appears critical to the out-of plane shear resistance of the structures, which results from the 
competition between the ASR-induced prestressing of reinforced concrete and the degradation of the materials properties. These results indicate that each structural configuration needs to be studied specifically. This implies, in particular, that large-scale laboratory test results may not be directly applicable to other in-situ structural configuration. However, these tests provide valuable data for the validation of structural models that can be applied subsequently to analyze the resilience of Safety Class I nuclear concrete structures under accidental scenarios. It is recommended that a full three-dimensional analysis of such structures be undertaken to further confirm this finding.

\section{Acknowledgements}

This research is sponsored by the U.S. Department of Energy (DOE) Light Water Reactor Sustainability Program. This manuscript has been authored by UT-Battelle, LLC under Contract No. DE-AC05-00OR22725 with the U.S. Department of Energy. The United States Government retains and the publisher, by accepting the article for publication, acknowledges that the United States Government retains a non-exclusive, paid-up, irrevocable, world-wide license to publish or reproduce the published form of this manuscript, or allow others to do so, for United States Government purposes. The Department of Energy will provide public access to these results of federally sponsored research in accordance with the DOE Public Access Plan (http://energy.gov/downloads/ doe-public-access-plan).

\section{Bibliography}

Akaike, H. (1974). A new look at statistical model identification. IEEE Transactions on Automatic Control, 19(6):716-723.

Bach, F., Thorsen, T., and Nielsen, M. (1993). Load-carrying capacity of structural members subjected to alkali-silica reactions. Construction and Building Materials, 7(2):109 - 115.

Blight, G. and Alexander, M. G. (2008). Alkali-Aggregate Reaction and Structural Damage to Concrete. Taylor \& Francis.

den Uijl, J. and Kaptijn, N. (2002). Structural Consequenses of ASR: an Example on Shear Capacity. HERON, 47(2):125-139. Special Issue on ASR.

den Uijl, J. and Kaptijn, N. (2003). Shear tests on beams cut from ASR-affected bridge decks. ACI Special Publication, 211(SP211-06):115-133.

Fan, S. and Hanson, J. (1998). Effect of alkali silica reaction expansion and cracking on structural behavior of reinforced concrete beams. ACI Structural Journal, 95(5):488-495. 
Giannini, E., Folliard, K., Zhu, J., Bayrak, O., Kreitman, K., Webb, Z., and Hanson, B. (2013). Non-Destructive Evaluation of In-Service Concrete Structures Affected by Alkali-Silica Reaction (ASR) or Delayed Ettringite Formation (DEF) - Final Report, Part I. Technical Report 0-6491-1, Center for Transportation Research The University of Texas at Austin and Texas A\&M Transportation Institute The Texas A\&M University System. Sponsoring Agency Name and Address Texas Department of Transportation Research and Technology Implementation Office P.O. Box 5080 Austin, TX 78763-5080.

Granger, L. (1995). Comportement différé du béton dans les enceintes de centrales nucléaires: analyse et modélisation. PhD thesis, Ecole Nationale des Ponts et Chaussées.

Haberman, S. (2013). Seabrook station nuclear plant license advancing. http: //www. seacoastonline.com/articles/20130515-NEWS-305150371. Retrieved June 2013.

Helsel, D. R. and Hirsch, R. M. (1992). Statistical methods in water resources, volume 49. Elsevier.

Larive, C. (1998). Apports Combinés de l'Expérimentation et de la Modélisation à la Compréhension de l'Alcali-Réaction et de ses Effets Mécaniques. $\mathrm{PhD}$ thesis, Laboratoire Central des Ponts et Chaussées, Paris.

Menétrey, P. and Willam, K. (1995). Triaxial failure criterion for concrete and its generalization. ACI Structural Journal, 92(3):311-318.

Miyagawa, T. (2013). Fracture of reinforcing steel in concrete damaged by ASR. Construction and Building Materials, 39:105-112.

ML121160422 (2012). Impact of alkali silica reaction on seabrook concrete structure. Technical Report ML121160422, NextEra.

Multon, S. (2004). Evaluation expérimentale et théorique des effets mécaniques de l'alcali-réaction sur des structures modèles. $\mathrm{PhD}$ thesis, Université de Marne la Vallée, France.

Nakamura, E., Watanabe, H., and Koga, H. (2008). Shear resisting mechanism in rc beams with stirrups fracture due to asr expansion. In Proceedings of the 13th International Conference on Alkali-Aggregate Reaction in Concrete.

R Core Team (2015). R: A Language and Environment for Statistical Computing. R Foundation for Statistical Computing, Vienna, Austria.

Rots, J. (1991). Smeared and discrete representations of localized fracture. International Journal of Fracture, 51:45-59.

Sanborn, I. (2015). Canadian utility closes n-plant plagued by ASR. http://www.newburyportnews.com/opinion/ canadian-utility-closes-n-plant-plagued-by-asr/article_ 7ba05ca3-ad76-5581-aa31-c7b84310d5b3.html. Retrieved Sept. 2015. 
Saouma, V. (2009). KumoNoSu, a 3d interactive graphics mesh generator for merlin; user's manual. http://civil.colorado.edu/ saouma/pdf/kumo. pdf.

Saouma, V. and Perotti, L. (2006a). Constitutive model for alkali-aggregate reactions. ACI Materials Journal, 103(3):194-2002.

Saouma, V. and Perotti, L. (2006b). Constitutive model for alkali aggregate reactions. ACI Materials Journal, 103(3):194-202.

Saouma, V., Červenka, J., and Reich, R. (2010). Merlin finite element user's manual. http://civil.colorado.edu/ saouma/pdf/users.pdf.

Schmidt, J., Hansen, S., Barbosa, R., and Henriksen, A. (2014). Novel shear capacity testing of asr damaged full scale concrete bridge. Engineering Structures, 79:365-374.

Shimizu, H., Watanabe, Y., Sekimoto, H., Oshima, R., Takiguchi, K., Masuda, Y., and Nishiguchi, I. (2005). Study on material properties in order to apply for structural analysis of turbine generator foundation affected by alkali-silica reaction. In 18th International Conference on Structural Mechanics in Reactor Technology (SMIRT 18), pages 2055-2060, Beijing, China. SMIRT18-H03-5.

Takatura, T., Ishikawa, T., Matsumoto, N., Mitsuki, S., Takiguchi, K., and Masuda, Y. (2005). Investigation of the expanded value of turbine generator foundation affected by alkali-silica reaction. In Proceedings of the 18th International Conference on Structural Mechanics in Reactor Technology (SMIRT18), number SMIRT18-H03-7, pages 2061-2068, Beijing, China.

Tcherner, J. and Aziz, T. (2009). Effects of aar on seismic assessment of nuclear power plants for life extensions. In Proceedings of the 20th International Conference on Structural Mechanics in Reactor Technology (SMIRT 20), number SMIRT20-Division 7 Paper 1789., Espoo, Finland.

Touma, W. (2000). Alkali-silica reaction in portland cement concrete: Testing methods and mitigation alternatives. Technical report, International Center for Aggregate Research.

Červenka, J. and Papanikolaou, V. (2008). Three dimensional combined fracture-plastic material model for concrete. International Journal of Plasticity, 24(12):2192-2220.

Wang, J. and Morikawa, H. (2012). Study on shear beahavior of deteriorated $\mathrm{RC}$ beams due to alkali-silica reaction. In 37th Conference on Our World in Concrete and Structures, Singpore. 


\section{Appendices}

\section{A. Multiple Linear Regression}

Multiple linear regression (MLR) is the extension of simple linear regression (SLR) to the case of multiple explanatory variables (which may or may not be truly independent). Hence, rather than modeling the mean response as a straight line, as in simple regression, it is now modeled as a function of several explanatory variables. The regression theory behind this approach, the procedures for parameter estimation, best model selection and hypothesis testing are very well developed and can be found in any standard staistics text book (Helsel and Hirsch, 1992). However, for the benefit of the reader we provide a brief description of the approach.

Multiple explanatory variables are required when scientific knowledge and experience tells us they are likely to be useful. In the problem at hand, this may be the depth of the beam, the maximum ASR expansion or others.

Simply put the model is:

$$
y=\beta_{0}+\sum_{i=1}^{n} \beta_{i} x_{i}+\varepsilon
$$

where $y$ is the response variable (such as shear strength variation), $\beta_{0}$ the intercept, $\beta_{i}$ is the slope coefficient of explanatory variable $i$, and $\varepsilon$ is the remaining unexplained noise in the date (the error), $x_{i}$ are all the constituents of the 18 variables listed in Table Table 8 , and the $\beta_{i}$ coefficients are to be determined.

Given the normalized approach taken by $\mathrm{R}$, a higher $\beta$ coefficient is indicative of a higher "participation factor" or relevant parameter in the shear strength change.

This equation will be solved by minimizing the error between data points and the estimated one (^):

$$
\hat{y}=\operatorname{argmin}(y-\hat{y})^{2}
$$

\section{A.1. Dummy Variables}

A categorical variable is one which is not continuous, yet it can take a value that is one of several possible categories.

In the statistical analysis of the results, none of the variables is continuous (such as load), but are rather dichotomous (such as depth of 24 " or 48 "), or (multiple) categorical variable, such as Boundary Conditions (U, R, or FR), or type of structure (B, TB or P). Yet internally statistical programs use numbers in all of their calculations, not words. So, even if one did not code dichotomous or multi-categorical variables using numbers, they will be converted by the program into numbers.

We can have R automatically do dummy variable coding, using a "factor" declaration. 


\section{A.2. Hypothesis Tests for Multiple Regression}

The single most important hypothesis test for MLR is the F test for comparing any two nested models. Let model "s" be the "simpler" MLR model

$$
y_{s}=\beta_{0}+\beta_{1} x_{1}+\beta_{2} x_{2}+\cdots+\beta_{k} x_{k}+\varepsilon_{s}
$$

It has $k+1$ parameters including the intercept, with degrees of freedom, dfs, of $n(k+1)$. Again, the degrees of freedom equals the number of observation minus the number of parameters estimated, as in SLR. Its sum of squared errors is $\mathrm{SSE}_{s}$.

Let model "c" be the more complex regression model

$$
y_{s}=\beta_{0}+\beta_{1} x_{1}+\beta_{2} x_{2}+\cdots+\beta_{k} x_{k}+\beta_{k+1} x_{k+1}+\cdots+\beta_{m} x_{m}+\varepsilon_{s}
$$

It has $m+1$ parameters and residual degrees of freedom, dfc, of $n(m+1)$. Its sum of squared errors is $\mathrm{SSE}_{c}$.

The test of interest is whether the more complex model provides a sufficiently better explanation of the variation in $y$ than does the simpler model. In other words, do the extra explanatory variables $x_{k+1}$ to $x_{m}$ add any new explanatory power to the equation? The models are "nested" because all of the $k$ explanatory variables in the simpler model are also present in the complex model, and thus the simpler model is nested within the more complex model. The null hypothesis is

$$
\begin{aligned}
& H_{0}: \quad \beta_{k+1}=\beta_{k+2}=\cdots=\beta_{m}=0 \quad \text { versus the alternative } \\
& H_{1} \quad: \quad \text { at least one of these } m k \text { coefficients is not equal to zero. }
\end{aligned}
$$

If the slope coefficients for the additional explanatory variables are all not significantly different from zero, the variables are not adding any explanatory power in comparison to the cost of adding them to the model. This cost is measured by the loss in the degrees of freedom $=m k$, the number of additional variables in the more complex equation.

The test statistic is

$$
F=\frac{\left(\mathrm{SSE}_{s}-\mathrm{SSE}_{c}\right)\left(\mathrm{df}_{s}-\mathrm{df}_{c}\right)}{\left(\mathrm{SSE}_{c} / \mathrm{df}_{c}\right)}
$$

where $\left(\mathrm{df}_{s}-\mathrm{df}_{c}\right)=m-k$.

If $F$ exceeds the tabulated value of the $F$ distribution with $\left(\mathrm{df}_{s}-\mathrm{df}_{c}\right)$ and $\mathrm{df}_{c}$ degrees of freedom for the selected $\alpha$ (say $\alpha=0.05$ ), then $H_{0}$ is rejected. Rejection indicates that the more complex model should be chosen in preference to the simpler model. If $F$ is small, the additional variables are adding little to the model, and the simpler model would be chosen over the more complex.

\section{A.3. Variable Selections: Akaike and Bayesian Information Criteria}

How can we decide what variables to include? Following Ockham's razor (or in Latin ex parsimoniae ) "Among competing hypotheses that predict equally 
well, the one with the fewest assumptions should be selected". In the context of MLR this means that a model with fewer parameters is to be preferred to one with more. However, this needs to be weighed against the ability of the model to actually predict anything.

Or one can say that the cost of adding additional variables is that the degrees of freedom decreases, making it more difficult to find significance in hypothesis tests and increasing the width of confidence intervals. Hence, a "good" model should explain as much of the variance of $y$ as possible with a small number of explanatory variables.

Two particular statistical models are considered:

Akaike Information Criterion (AIC) is one of the most common model selection for model selection procedure that is available in most statistical software packages. It is based on maximum likelihood and a penalty for each parameter, (Akaike, 1974). For each model, compute

$$
\mathrm{AIC}=n \ln (\mathrm{SSE})-n \ln (n)+2 p
$$

where SSE is the usual residual sum of squares from that model, $p$ is the number of parameters in the current model, and $n$ is the sample size. After doing this for all possible models, the "best" model is the one with the smallest AIC.

Note that the AIC is formed from three terms: The first is a measure of fit, since $n \ln (\mathrm{SSE})$ is essentially the sum of squared residuals. The second term, $n \ln (n)$ is a constant, and really plays no role in selecting the model. The third term, $2 p$ is a "penalty" term for adding more terms to the model. This is because the first term always decreases as more terms are added into the model, so this is needed for "balance".

Schwartz's Bayesian information criterion (BIC) is similar to AIC, but penalizes additional parameters more. For each model, calculate:

$$
\mathrm{BIC}=n \ln (\mathrm{SSE})-n \ln (n)+\ln (n) p
$$

Where SSE is the usual residual sum of squares from that model, $p$ is the number of parameters in the current model, and $n$ is the sample size. After doing this for all possible models, the "best" model is the one with the smallest BIC. Note the similarity between AIC and BIC, the penalty term in $\mathrm{BIC}$ is larger than that in $\mathrm{AIC}$ - hence, BIC based best models tend to be more parsimonious compared to AIC.

\section{A.4. $R$ Listing and Output}

The command in R used for linear fitting is "lm". It can be used to carry out regression, single stratum analysis of variance and analysis of covariance. The following short and elegant sample code is at the heart of the procedure.

The results of the linear model fitting are provided in a table including the $\beta_{i}$ coefficients for the most relevant sub-variables, their standard deviation, $t$ and $\operatorname{Pr}(>|t|)$ (previously defined) are also reported. 
Estimated Coefficient: is the value of slope calculated by the regression. It might seem a little confusing that the Intercept also has a value, but should be interpreted as a slope that is always multiplied by 1 . This number will obviously vary based on the magnitude of the variable which is going to be an input into the regression, but it is always good practice to spot check this number to evaluate its reasonableness.

Standard Error of the Coefficient Estimate : Measure of the variability in the estimate for the coefficient. Lower means better but this number is relative to the value of the coefficient. As a rule of thumb, this value should to be at least an order of magnitude less than the coefficient estimate.

$t$ : Score that measures whether or not the coefficient for this variable is meaningful for the model.

$\operatorname{Pr}(>|t|)$ : A predictor that has a low p-value is likely to be a meaningful addition to model because changes in the predictor's value are related to changes in the response variable A large p-value suggests that changes in the predictor are not associated with changes in the response. Hence this number should be as small as possible.

Significance Stars : The stars are shorthand for significance levels, with the number of asterisks displayed according to the $p$-value computed. $* * *$ for high significance and $*$ for low significance.

\section{Abbreviations}

$\begin{array}{ll}\text { AAR } & \text { alkali-aggregate reaction } \\ \text { ASR } & \text { alkali-silica reaction } \\ \text { AIC } & \text { Akaike Information Criterion } \\ \text { BIC } & \text { Bayesian Information Criterion } \\ \text { BC } & \text { boundary condition } \\ \text { B } & \text { beam } \\ \text { CCB } & \text { concrete containment building } \\ \text { DOT } & \text { Department of Transportation } \\ \text { FR } & \text { fully restrained } \\ \text { IN } & \text { Information Notice } \\ \text { IQR } & \text { interquartile range } \\ \text { LWR } & \text { light water reactor } \\ \text { MLR } & \text { multiple linear regression } \\ \text { NPP } & \text { nuclear power plant } \\ \text { NRC } & \text { Nuclear Regulatory Commission } \\ \text { P } & \text { panel } \\ \text { PDF } & \text { probability distribution function } \\ \text { PWR } & \text { pressurized water reactor }\end{array}$




$\begin{array}{ll}\text { Q1 } & \text { first quartile } \\ \text { Q2 } & \text { second quartile } \\ \text { Q3 } & \text { third quartile } \\ \text { R } & \text { restrained } \\ \text { RC } & \text { reinforced concrete } \\ \text { SLR } & \text { simple linear regression } \\ \text { SSE } & \text { sum of squared errors } \\ \text { TB } & \text { truncated beam } \\ \text { U } & \text { unrestrained }\end{array}$


Table 1: Boundary conditions for ASR expansion and shear loading

\begin{tabular}{|c|c|c|c|c|c|c|c|c|c|c|c|c|c|c|c|c|}
\hline \multirow[t]{2}{*}{ Spec. } & \multirow[t]{2}{*}{$\mathrm{BC}$} & \multicolumn{3}{|c|}{ Bottom } & \multicolumn{3}{|c|}{ Front } & \multicolumn{3}{|c|}{ Back } & \multicolumn{3}{|c|}{ Left } & \multicolumn{3}{|c|}{ Right } \\
\hline & & $x$ & $y$ & $z$ & $x$ & $y$ & $z$ & $x$ & $y$ & $z$ & $x$ & $y$ & $z$ & $x$ & $y$ & $z$ \\
\hline \multicolumn{17}{|c|}{ ASR Expansion (Increments $=1$ to 73 ) } \\
\hline \multirow{3}{*}{$\mathrm{B}$} & $\mathrm{U}$ & - & - & $\bullet$ & - & - & - & - & - & - & & $\mathrm{I}$ & & & - & - \\
\hline & $\mathrm{R}$ & - & - & • & - & $\bullet$ & - & - & $\bullet$ & - & • & - & - & & - & - \\
\hline & FR & - & - & - & $\bullet$ & $\bullet$ & • & • & $\bullet$ & $\bullet$ & $\bullet$ & $\bullet$ & $\bullet$ & • & $\bullet$ & $\bullet$ \\
\hline \multirow{3}{*}{ TB } & $\mathrm{U}$ & - & - & $\bullet$ & - & - & - & - & - & - & & II & & & - & - \\
\hline & $\mathrm{R}$ & - & - & $\bullet$ & - & $\bullet$ & - & - & $\bullet$ & - & $\bullet$ & - & - & & - & - \\
\hline & FR & - & - & - & $\bullet$ & $\bullet$ & • & $\bullet$ & $\bullet$ & $\bullet$ & $\bullet$ & $\bullet$ & $\bullet$ & $\bullet$ & $\bullet$ & $\bullet$ \\
\hline \multirow{3}{*}{$\mathrm{P}$} & $\mathrm{U}$ & - & - & $\bullet$ & - & - & - & - & - & - & & III & - & & - & - \\
\hline & $\mathrm{R}$ & - & - & • & - & $\bullet$ & - & - & $\bullet$ & - & $\bullet$ & - & - & & - & - \\
\hline & FR & - & - & - & $\bullet$ & $\bullet$ & • & $\bullet$ & $\bullet$ & $\bullet$ & $\bullet$ & $\bullet$ & • & • & $\bullet$ & $\bullet$ \\
\hline \multicolumn{17}{|c|}{ Shear Load (Increments $=74$ to 174$)$} \\
\hline \multirow{3}{*}{$\mathrm{B}$} & $\mathrm{U}$ & & IV & & - & - & - & - & - & - & - & - & - & - & - & - \\
\hline & $\mathrm{R}$ & & IV & & - & $\bullet$ & - & - & $\bullet$ & $\bullet$ & - & - & $\bullet$ & - & - & - \\
\hline & FR & & IV & & $\bullet$ & $\bullet$ & - & $\bullet$ & $\bullet$ & - & $\bullet$ & • & - & $\bullet$ & $\bullet$ & - \\
\hline \multirow{3}{*}{ TB } & $\mathrm{U}$ & & $\mathrm{V}$ & & - & - & - & - & - & - & - & - & - & & - & - \\
\hline & $\mathrm{R}$ & & $\mathrm{V}$ & & - & • & - & - & • & - & & - & - & & - & - \\
\hline & $\mathrm{FR}$ & & $\mathrm{V}$ & & • & • & - & • & $\bullet$ & - & • & $\bullet$ & $\bullet$ & • & $\bullet$ & - \\
\hline \multirow{3}{*}{$\mathrm{P}$} & $\mathrm{U}$ & - & - & - & - & - & - & - & - & - & & $\mathrm{VI}$ & - & & - & - \\
\hline & $\mathrm{R}$ & - & - & - & - & • & - & - & $\bullet$ & - & & VI & - & & - & - \\
\hline & FR & - & - & - & $\bullet$ & • & - & $\bullet$ & $\bullet$ & - & $\bullet$ & $\bullet$ & $\bullet$ & & $\bullet$ & - \\
\hline
\end{tabular}

Dash (-): No surface boundary condition

Bullet $(\bullet)$ : Restrained surface boundary condition

I: Bottom edge restrained in $\mathrm{x}$-dir; bottom corner vertex restrained in $\mathrm{y}$-dir

II: Bottom corner vertex restrained in y-dir

III: Bottom corner vertex restrained in y-dir

IV: Left support restrained in three directions; right one only in z-dir

$\mathrm{V}$ : The only left support restrained in three directions

VI: Bottom edge restrained in y- and z-dir

Note: This table should be used in conjunction with Figure 3 and Figure 4

$\mathrm{x}$-dir: longitudinal direction

y-dir: out-of-plane direction

z-dir: vertical (gravitational) direction

Bottom face: $z=0$; Top face: $z=$ thickness

Left face: $x=0$; Right face: $x=$ length

Front face: $y=0$; Back face: $y=$ width 
Table 2: Models dimensions in inch (meter)

\begin{tabular}{|c|c|c|c|c|c|c|c|c|c|c|}
\hline Model & $\begin{array}{l}\text { Sub- } \\
\text { model }\end{array}$ & $a_{1}$ & $a_{2}$ & $a_{3}$ & $\mathrm{a}_{4}$ & $a_{5}$ & d & $\mathrm{L}_{\text {tot }}$ & $\mathrm{w}$ & $\mathrm{t}$ \\
\hline B & B2 & $\begin{array}{l}8 \\
(0.2032) \\
8 \\
(0.2032)\end{array}$ & $\begin{array}{l}4 \\
(0.1016) \\
4 \\
(0.1016)\end{array}$ & $\begin{array}{l}51.5 \\
(1.3081) \\
111.5 \\
(2.8321)\end{array}$ & $\begin{array}{l}4 \\
(0.1016) \\
4 \\
(0.1016)\end{array}$ & $\begin{array}{l}111 \\
(2.8194) \\
231 \\
(5.8674)\end{array}$ & $\begin{array}{l}23 \\
(0.5842) \\
47 \\
(1.1938)\end{array}$ & $\begin{array}{l}190.5 \\
(4.8387) \\
370.5 \\
(9.4107) \\
\end{array}$ & $\begin{array}{l}48 \\
(1.2192) \\
96 \\
(2.4384)\end{array}$ & $\begin{array}{l}24 \\
(0.6096) \\
48 \\
(1.2192)\end{array}$ \\
\hline TB & TB2 & $\begin{array}{l}8 \\
(0.2032) \\
8 \\
(0.2032)\end{array}$ & $\begin{array}{l}4 \\
(0.1016) \\
4 \\
(0.1016)\end{array}$ & $\begin{array}{l}51.5 \\
(1.3081) \\
111.5 \\
(2.8321) \\
\end{array}$ & $\begin{array}{l}4 \\
(0.1016) \\
4 \\
(0.1016)\end{array}$ & - & $\begin{array}{l}23 \\
(0.5842) \\
47 \\
(1.1938) \\
\end{array}$ & $\begin{array}{l}67.5 \\
(1.7145) \\
127.5 \\
(3.2385) \\
\end{array}$ & $\begin{array}{l}48 \\
(1.2192) \\
96 \\
(2.4384)\end{array}$ & $\begin{array}{l}24 \\
(0.6096) \\
48 \\
(1.2192)\end{array}$ \\
\hline $\mathrm{P}$ & P2 & - & - & - & $\begin{array}{l}4 \\
(0.1016) \\
4 \\
(0.1016)\end{array}$ & - & $\begin{array}{l}23 \\
(0.5842) \\
47 \\
(1.1938)\end{array}$ & $\begin{array}{l}57.5 \\
(1.4605) \\
117.5 \\
(2.9845)\end{array}$ & $\begin{array}{l}48 \\
(1.2192) \\
96 \\
(2.4384)\end{array}$ & $\begin{array}{l}24 \\
(0.6096) \\
48 \\
(1.2192)\end{array}$ \\
\hline
\end{tabular}

R1C3-G

Table 3: Finite Element Mesh Characteristics

\begin{tabular}{lrr}
\hline Geometry & \# of Nodes & \# of Elements \\
\hline Beam & 1,520 & 1.036 \\
Truncated Beam & 1,323 & 960 \\
Panel & 2,233 & 1,680 \\
\hline
\end{tabular}

Table 4: Varying parameters

\begin{tabular}{ll}
\hline Variable & Values \\
\hline & ASR Expansion + Shear Loading \\
Geometry & Beam (B), Truncated Beam (TB), Panel (P) \\
Boundary Conditions & Unrestrained, Restrained, Partially Restrained \\
Thickness & $2 \mathrm{ft}(0.6096 \mathrm{~m}), 4 \mathrm{ft}(1.2192 \mathrm{~m})$ \\
Reinforcement Ratio & $0.2 \%(0.002), 0.5 \%(0.005), 1 \%(0.010)$ \\
ASR Expansion & $0.1 \%(0.001), 0.2 \%(0.002), 0.3 \%(0.003)$ \\
Residual Elastic Modulus & $0.7,0.9$ \\
Residual Tensile Strength & $0.7,0.9$ \\
\hline & Shear Loading \\
Geometry & Beam (B), Truncated Beam (TB), Panel (P) \\
Boundary Conditions & Unrestrained, Restrained, Partially Restrained \\
Thickness & $2 \mathrm{ft}(0.6096 \mathrm{~m}), 4 \mathrm{ft}(1.2192 \mathrm{~m})$ \\
Reinforcement Ratio & $0.2 \%(0.002), 0.5 \%(0.005), 1 \%(0.010)$ \\
\hline
\end{tabular}


Table 5: Concrete mechanical properties (smeared crack model)

\begin{tabular}{lllr}
\hline Characteristics & Symbol & Unit & Value \\
\hline Mass density & $\rho$ & $\mathrm{kg} \mathrm{m}^{-3}$ & 2,250 \\
Modulus of elasticity & $E$ & $\mathrm{MPa}$ & 26,000 \\
Poisson's ratio & $\nu$ & - & 0.2 \\
Tensile strength & $f_{t}$ & $\mathrm{MPa}$ & 3.1 \\
Fracture energy (Exponential softening) & $G_{F}$ & $\mathrm{~N} \mathrm{~m}^{-1}$ & 150 \\
Compressive strength & $f_{c}$ & $\mathrm{MPa}$ & -31.0 \\
Critical displacement in compression & $w_{d}$ & $\mathrm{~mm}$ & -0.5 \\
Factor beta for return direction & $\beta$ & - & 0 \\
Factor e for roundness of failure surface & $e$ & - & 0.55 \\
Onset of nonlinearity in compression & $f_{c_{0}}$ & $\mathrm{MPa}$ & -20.0 \\
Plastic strain at compressive strength & $\epsilon_{c p}$ & - & $-1 \%$ \\
\hline
\end{tabular}

Table 6: Characteristics of the ASR model. ATU: arbitrary time unit

\begin{tabular}{lllr}
\hline Characteristics & Symbol & Unit & Value \\
\hline Reference temperature & $T_{0}$ & ${ }^{\circ} \mathrm{C}$ & 35 \\
Maximum volumetric expansion at $T_{0}^{\text {test }}$ & $\varepsilon_{A S R}^{\infty}$ & - & $0.1 \%, 0.2 \%$ \\
Characteristic time at $T_{0}^{\text {test }}$ & $\tau_{C}$ & $\mathrm{ATU}$ & $7.3 \%$ \\
Latency time at $T_{0}^{\text {test }}$ & $\tau_{L}$ & $\mathrm{ATU}$ & 17.71 \\
Activation energy for $\tau_{C}$ & $U_{C}$ & $\mathrm{~K}$ & 5,400 \\
Activation energy for $\tau_{L}$ & $U_{L}$ & $\mathrm{~K}$ & 9,400 \\
Residual reduction factor & $\Gamma_{r}$ & - & 0.5 \\
Fraction of $\varepsilon_{t}$ prior to reduction of ASR ex- & $\gamma_{t}$ & - & 0.5 \\
pansion due to macro cracking & & & -8 \\
ASR expansion annealing stress & $\sigma_{U}$ & $\mathrm{MPa}$ & $70 \%, 90 \%$ \\
Post-ASR residual relative Young modulus & $\beta_{E}$ & - & $70 \%, 90 \%$ \\
Post-ASR residual tensile strength & $\beta_{f_{t}}$ & - & \\
\hline
\end{tabular}

Table 7: Materials Properties and ratios of reinforcing bars

\begin{tabular}{lllc}
\hline Characteristics & Symbol & Unit & Value \\
\hline Reinforcement ratio & $\rho$ & - & $0.002,0.005$ and 0.01 \\
Elastic modulus & $\mathrm{E}$ & $\mathrm{MPa}$ & 200,000 \\
Poisson's ratio & $\nu$ & - & 0.3 \\
Yield stress & $\sigma_{Y}$ & $\mathrm{MPa}$ & 248 \\
\hline
\end{tabular}


Table 8: Main classes of variables and R Sub-variables

\begin{tabular}{|c|c|c|c|c|}
\hline Main & Variables & Analyses & Normalized $\mathbf{R}$ & R Sub-variables \\
\hline \multirow{3}{*}{1} & \multirow{3}{*}{ Type } & $\mathrm{B}$ & 1 & 1 \\
\hline & & TB & 2 & 2 \\
\hline & & $\mathrm{P}$ & 3 & 3 \\
\hline \multirow{2}{*}{2} & \multirow{2}{*}{ Depth } & $24 "$ & 2 & 4 \\
\hline & & $48 "$ & 4 & 5 \\
\hline \multirow{3}{*}{3} & \multirow{3}{*}{ B.C. } & $\mathrm{U}$ & 1 & 6 \\
\hline & & $\mathrm{R}$ & 2 & 7 \\
\hline & & FR & 3 & 8 \\
\hline \multirow{3}{*}{4} & \multirow{3}{*}{$\varepsilon$} & 0.001 & 1 & 9 \\
\hline & & 0.002 & 2 & 10 \\
\hline & & 0.003 & 3 & 11 \\
\hline \multirow{3}{*}{5} & \multirow{3}{*}{$\rho$} & 0.002 & 1 & 12 \\
\hline & & 0.005 & 2 & 13 \\
\hline & & 0.01 & 3 & 14 \\
\hline \multirow{2}{*}{6} & \multirow{2}{*}{$\beta_{E}$} & 0.7 & 1 & 15 \\
\hline & & 0.9 & 2 & 16 \\
\hline \multirow{2}{*}{7} & \multirow{2}{*}{$\beta_{f t}$} & 0.7 & 1 & 17 \\
\hline & & 0.9 & 2 & 18 \\
\hline
\end{tabular}

Table 9: Summary of linear model fitting

\begin{tabular}{|c|c|c|c|c|c|c|c|c|c|c|}
\hline & \multicolumn{3}{|c|}{ Full Set } & \multicolumn{3}{|c|}{ Positive Set } & \multicolumn{3}{|c|}{ Negative Set } \\
\hline & & General & AIC & $\mathrm{BIC}$ & General & AIC & BIC & General & AIC & BIC \\
\hline 1 & Type B & & & & & & & & & \\
\hline 2 & Type TB & 4 & 4 & & & & & 5 & 5 & 5 \\
\hline 3 & Type P & 6 & 6 & & & & & 4 & 4 & 3 \\
\hline 4 & Depth 2 & & & & & & & & & \\
\hline 5 & Depth 4 & & & & 6 & 7 & 7 & & & \\
\hline 6 & B.C. U & & & & & & & & & \\
\hline 7 & B.C. $\mathrm{R}$ & 7 & 7 & 5 & 1 & 1 & 1 & 1 & 1 & 1 \\
\hline 8 & B.C. FR & 2 & 2 & 2 & 4 & 4 & 4 & 6 & 6 & 6 \\
\hline 9 & $\epsilon 0.001$ & & & & & & & & & \\
\hline 10 & $\epsilon 0.002$ & & & 7 & 7 & 6 & 6 & & & 7 \\
\hline 11 & $\epsilon 0.003$ & 3 & 3 & 3 & 5 & 5 & 5 & 2 & 2 & 2 \\
\hline 12 & $\rho 0.002$ & & & & & & & & & \\
\hline 13 & $\rho 0.005$ & & & 6 & & & & & & \\
\hline 14 & $\rho 0.010$ & 1 & 1 & 1 & 2 & 2 & 2 & 3 & 3 & 4 \\
\hline 15 & $\beta_{E} 0.7$ & & & & & & & & & \\
\hline 16 & $\beta_{E} 0.9$ & & & & & & & 7 & 7 & \\
\hline 17 & $\beta_{f t} 0.7$ & & & & & & & & & \\
\hline 18 & $\beta_{f t} 0.9$ & 5 & 5 & 4 & 3 & 3 & 3 & & & \\
\hline
\end{tabular}


Table 10: Three Fitting Models for Positive Shear Strength Data Set; (restrained model only)

\begin{tabular}{|c|c|c|c|c|c|c|}
\hline & Coefficients: & Estimate & Std. error & t value & $\operatorname{Pr}(>|t|)$ & Signif. \\
\hline \multirow{10}{*}{ 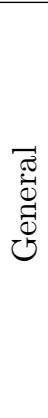 } & (Intercept) & 48.887 & 11.795 & 4.145 & $9.16 \mathrm{E}-05$ & $* * *$ \\
\hline & $\mathrm{TB}$ & -9.443 & 5.384 & -1.754 & 0.083711 & \\
\hline & $\mathrm{P}$ & -12.887 & 5.196 & -2.48 & 0.01546 & * \\
\hline & $48 "$ & -6.444 & 4.804 & -1.341 & 0.183982 & \\
\hline & $\varepsilon^{\infty}=0.002$ & 7.699 & 4.728 & 1.628 & 0.107809 & \\
\hline & $\varepsilon^{\infty}=0.003$ & 4.478 & 5.645 & 0.793 & 0.430251 & \\
\hline & $\rho=0.005$ & -28.164 & 9.588 & -2.937 & 0.004442 & $* *$ \\
\hline & $\rho=0.01$ & -16.081 & 9.585 & -1.678 & 0.097734 & \\
\hline & $\beta_{E}=0.9$ & 2.996 & 4.287 & 0.699 & 0.486908 & \\
\hline & $\beta_{f t}=0.9$ & 15.207 & 4.277 & 3.556 & 0.000671 & $* * *$ \\
\hline \multirow{7}{*}{$\underset{Z}{\stackrel{Z}{Z}}$} & (Intercept) & 56.016 & 10.688 & 5.241 & $1.42 \mathrm{E}-06$ & $* * *$ \\
\hline & TB & -9.993 & 5.342 & -1.871 & 0.065292 & \\
\hline & $\mathrm{P}$ & -13.615 & 5.162 & -2.638 & 0.01014 & * \\
\hline & $48 "$ & -7.074 & 4.782 & -1.479 & 0.143296 & \\
\hline & $\rho=0.005$ & -29.831 & 9.413 & -3.169 & 0.002215 & $* *$ \\
\hline & $\rho=0.01$ & -17.79 & 9.376 & -1.897 & 0.061634 & \\
\hline & $\beta_{f t}=0.9$ & 15.598 & 4.267 & 3.655 & 0.000474 & $* * *$ \\
\hline \multirow{4}{*}{$\stackrel{\circlearrowright}{\varrho}$} & (Intercept) & 41.581 & 9.414 & 4.417 & $3.19 \mathrm{E}-05$ & $* * *$ \\
\hline & $\rho=0.005$ & -27.611 & 9.53 & -2.897 & 0.00488 & $* *$ \\
\hline & $\rho=0.01$ & -13.706 & 9.224 & -1.486 & 0.14133 & \\
\hline & $\beta_{f t}=0.9$ & 14.806 & 4.417 & 3.352 & 0.00124 & $* *$ \\
\hline
\end{tabular}

Note: The stars are shorthand for significance levels. ${ }^{* * *}$ for high significance and $*$ for low significance. 
Table 11: Three Fitting Models for Negative Shear Strength Data Set; (restrained model only)

\begin{tabular}{|c|c|c|c|c|c|c|}
\hline & Coefficients: & Estimate & Std. error & t value & $\operatorname{Pr}(>|t|)$ & Signif. \\
\hline \multirow{10}{*}{ 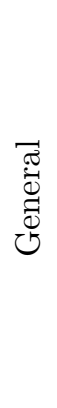 } & (Intercept) & -15.6835 & 8.7845 & -1.785 & 0.0772 & \\
\hline & $\mathrm{TB}$ & -12.1158 & 8.0128 & -1.512 & 0.1336 & \\
\hline & $\mathrm{P}$ & -10.0268 & 7.6347 & -1.313 & 0.192 & \\
\hline & $48 "$ & -13.6526 & 6.4079 & -2.131 & 0.0355 & * \\
\hline & $\varepsilon^{\infty}=0.002$ & -9.0327 & 7.612 & -1.187 & 0.2381 & \\
\hline & $\varepsilon^{\infty}=0.003$ & -45.1145 & 7.5992 & -5.937 & $4.04 \mathrm{E}-08$ & $* * *$ \\
\hline & $\rho=0.005$ & -4.61 & 6.6249 & -0.696 & 0.4881 & \\
\hline & $\rho=0.01$ & -20.2409 & 10.1427 & -1.996 & 0.0486 & * \\
\hline & $\beta_{E}=0.9$ & 5.7823 & 6.0569 & 0.955 & 0.342 & \\
\hline & $\beta_{f t}=0.9$ & -0.3567 & 6.0729 & -0.059 & 0.9533 & \\
\hline \multirow{6}{*}{ 导 } & (Intercept) & -20.639 & 6.384 & -3.233 & 0.00163 & $* *$ \\
\hline & $48^{\prime \prime}$ & -13.423 & 6.139 & -2.186 & 0.03098 & * \\
\hline & $\varepsilon^{\infty}=0.002$ & -9.436 & 7.569 & -1.247 & 0.21527 & \\
\hline & $\varepsilon^{\infty}=0.003$ & -45.082 & 7.557 & -5.965 & $3.27 \mathrm{E}-08$ & $* * *$ \\
\hline & $\rho=0.005$ & -4.462 & 6.586 & -0.677 & 0.49956 & \\
\hline & $\rho=0.01$ & -22.453 & 9.607 & -2.337 & 0.02131 & * \\
\hline \multirow{3}{*}{$=$} & (Intercept) & -28.141 & 5.588 & -5.036 & $1.90 \mathrm{E}-06$ & $* * *$ \\
\hline & $\varepsilon^{\infty}=0.002$ & -11.857 & 7.741 & -1.532 & 0.128 & \\
\hline & $\varepsilon^{\infty}=0.003$ & -50.139 & 7.558 & -6.634 & 1.31E-09 & $* * *$ \\
\hline
\end{tabular}

Note: The stars are shorthand for significance levels. *** for high significance and $*$ for low significance.

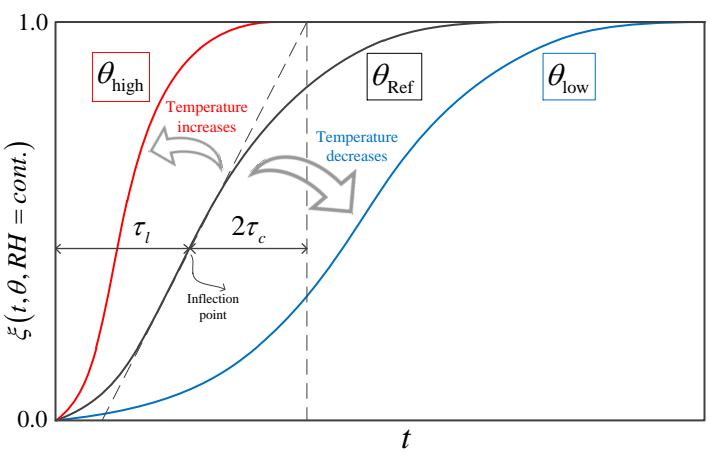

Figure 1: Physical interpretation of parameters describing the swelling evolution of an ASR affected concrete Larive (1998) 


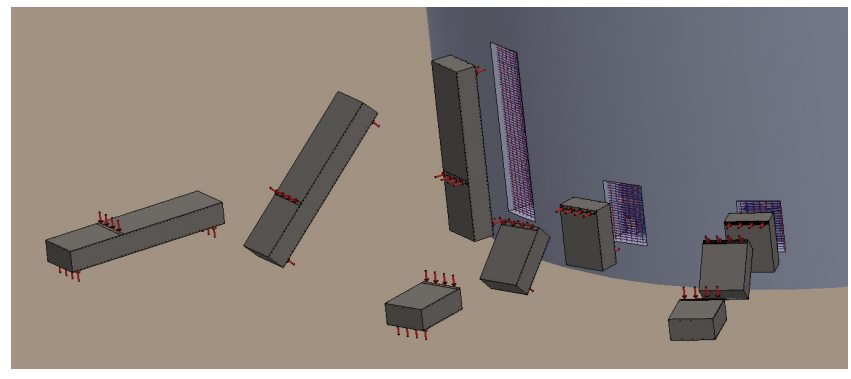

Figure 2: From Containment Shell to Concrete Model (Beam, Truncated Beam and Panel) 


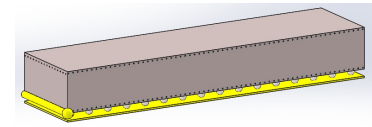

(a) B; U; ASR

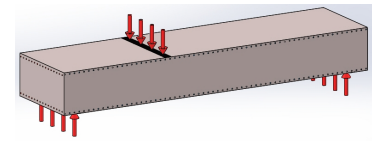

(d) B; U; Shear

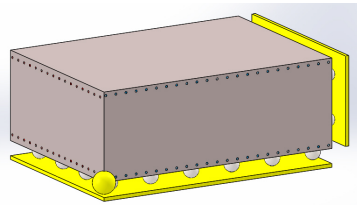

(g) TB; U; ASR

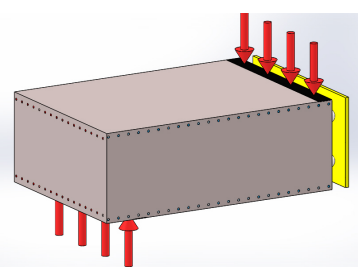

(j) TB; U; Shear

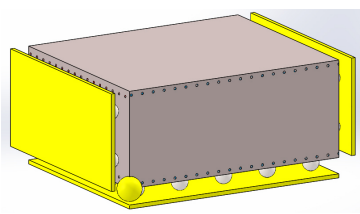

(m) P; U; ASR

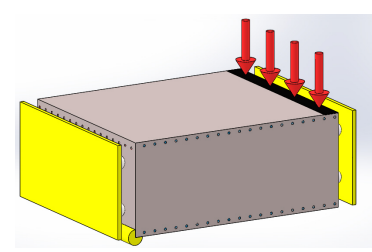

(p) P; U; Shear

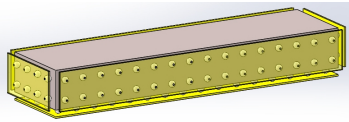

(b) B; R; ASR

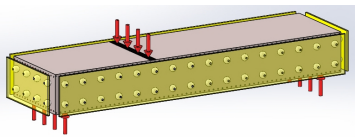

(e) B; R; Shear

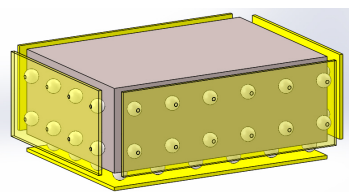

(h) TB; R; ASR

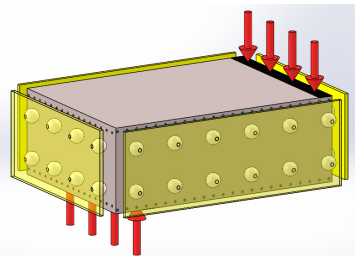

(k) TB; R; Shear

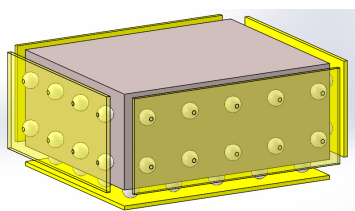

(n) P; R; ASR

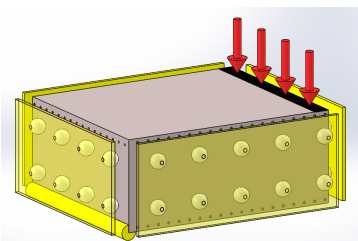

(q) P; R; Shear

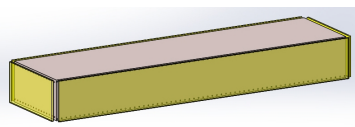

(c) B; FR; ASR

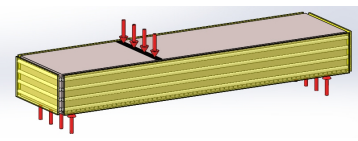

(f) B; FR; Shear

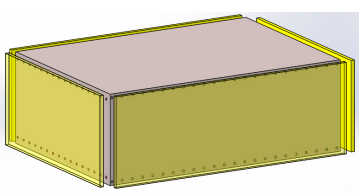

(i) TB; FR; ASR

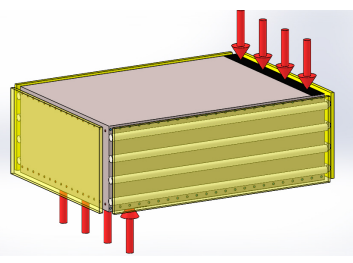

(l) TB; FR; Shear

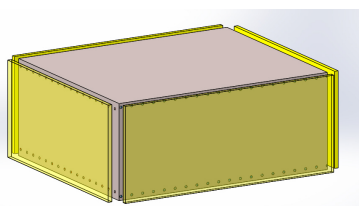

(o) P; FR; ASR

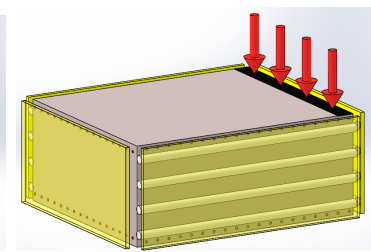

(r) P; FR; Shear

Figure 3: Unrestrained (U), Restrained (R) and Fully Restrained (FR) boundary conditions for the Beam (B), Truncated Beam (TB) and Panel (P) models; (Single orb = vertex restriction; group of orbs = restriction in perpendicular direction on surface; single rod = edge restriction; group of rods $=$ roller boundary conditions on surface) 


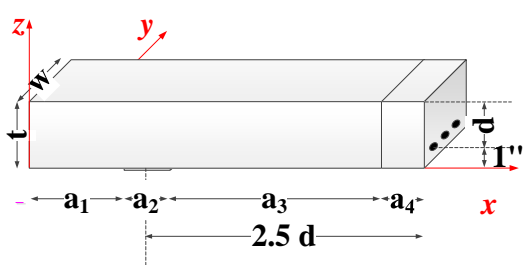

(a) Truncated Beam

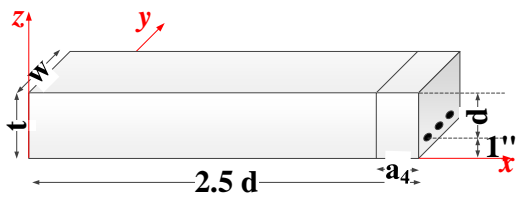

(b) Panel

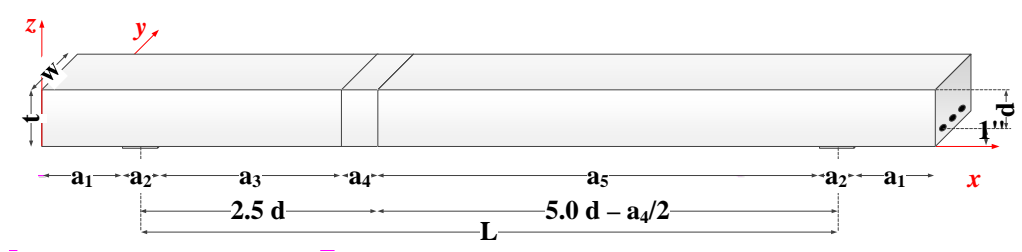

(c) Beam

Figure 4: Dimensions

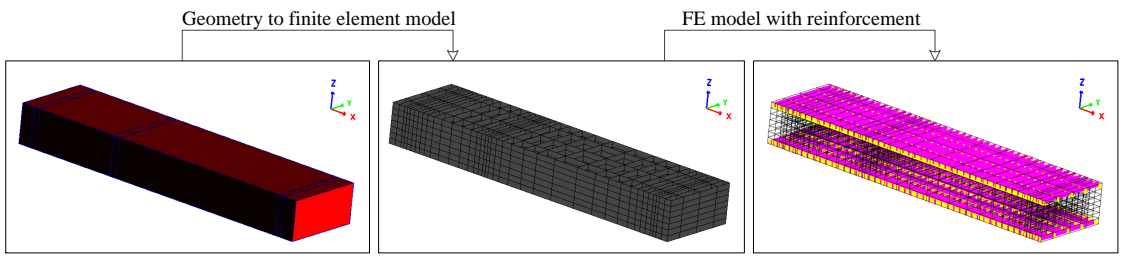

$\mathrm{R} 2 \mathrm{C} 3$

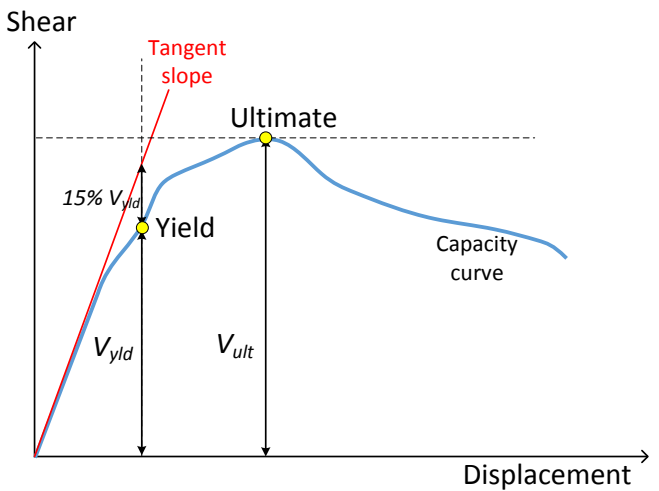

Figure 6: Definition of yield and ultimate points on the capacity curve 

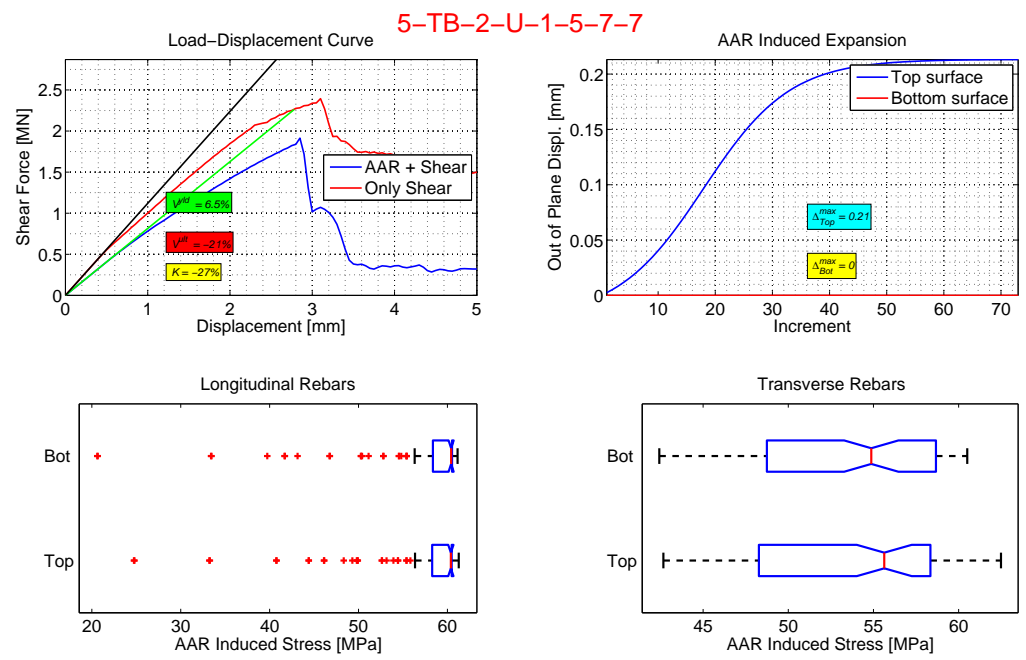

(a) Sample of shear strength reduction
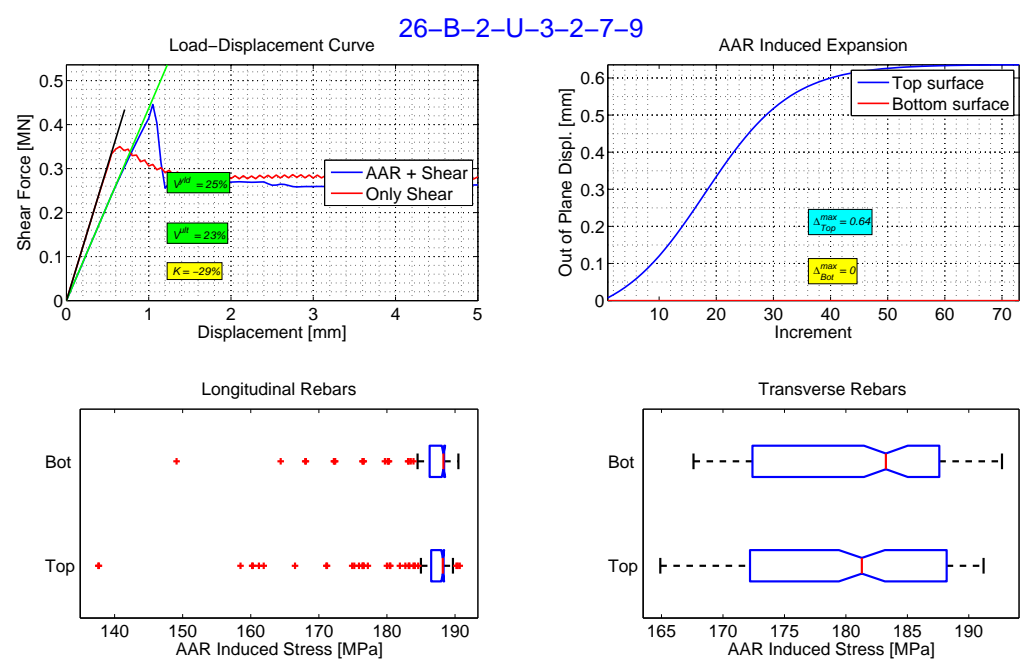

(b) Sample of shear strength gain

Figure 7: Examples of all individual 2D plots 

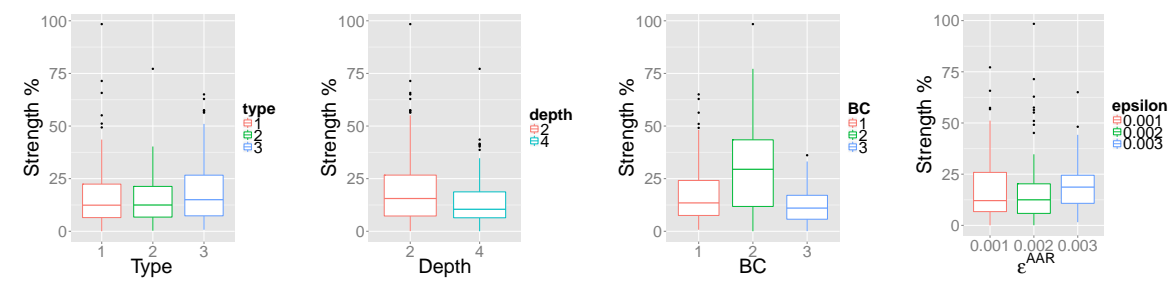

(a) Type: B, TB, P

(b) Depth: 24", 48"

(c) BC: U, R, FR

(d) $\varepsilon^{A S R}$

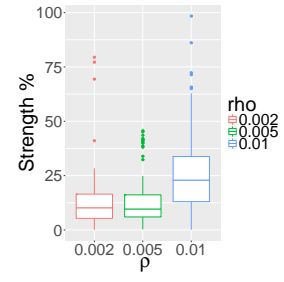

(e) $\rho$

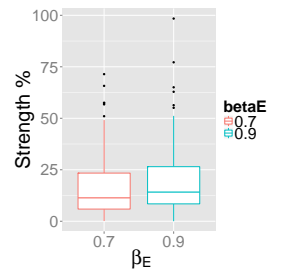

(f) $\beta_{E}$

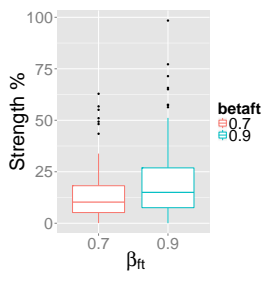

(g) $\beta_{f t}$

Figure 8: Boxplots for Shear Strength Increase in terms of each of the seven variables

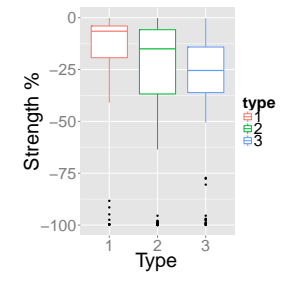

(a) Type: B, TB, P

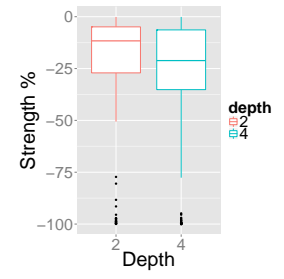

(b) Depth: 24", 48"

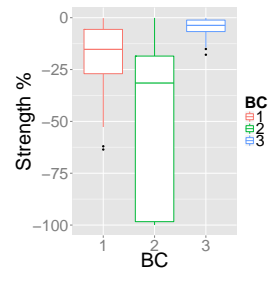

(c) BC: U, R, FR

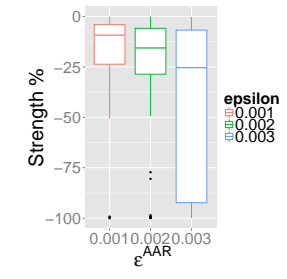

(d) $\varepsilon^{A S R}$

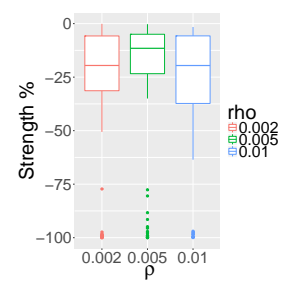

(e) $\rho$

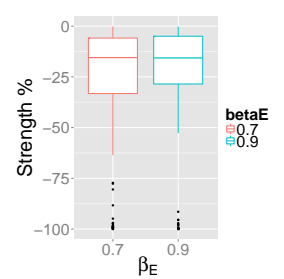

(f) $\beta_{E}$

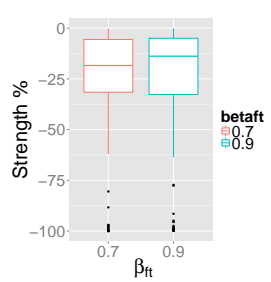

(g) $\beta_{f t}$

Figure 9: Boxplots for Shear Strength Decrease in terms of each of the seven variables 

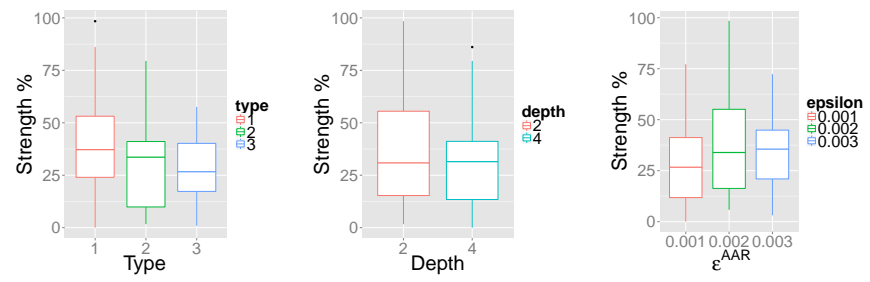

(a) Type: B, TB, P

(b) Depth: 24", 48"

(c) $\varepsilon^{A S R}$
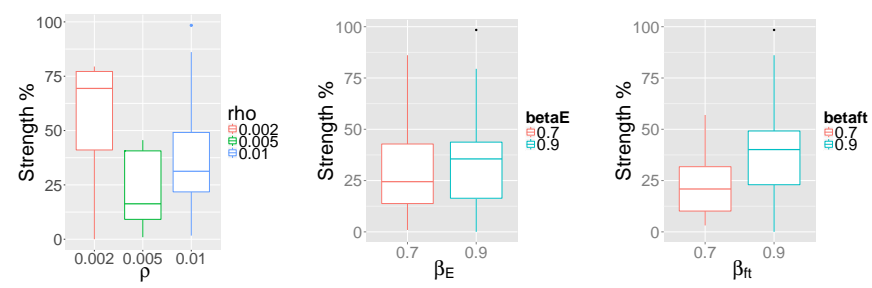

(d) $\rho$

(e) $\beta_{E}$

(f) $\beta_{f t}$

Figure 10: Boxplots for Shear Strength Increase in terms of each of the six variables; only restrained model

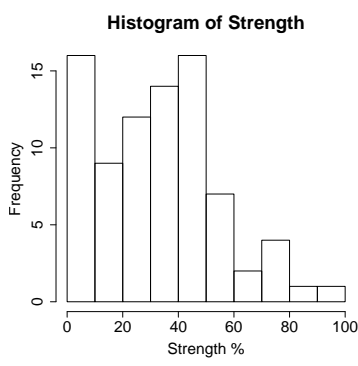

(a) Histogram

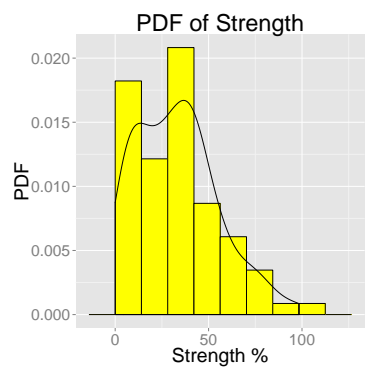

(b) Probability Distribution Function

Figure 11: Histograms for Shear Strength Increase; only restrained model 

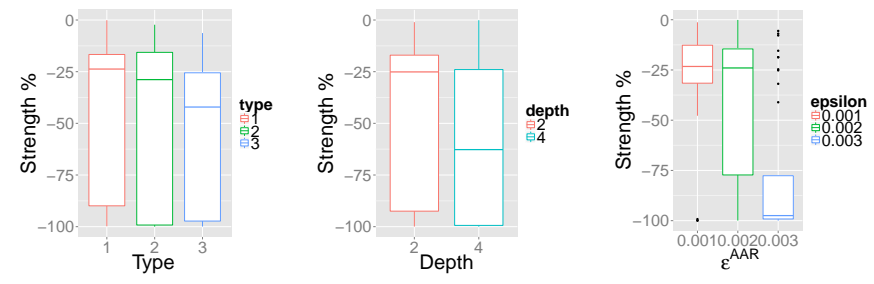

(a) Type: B, TB, P

(b) Depth: 24", 48"

(c) $\varepsilon^{A S R}$
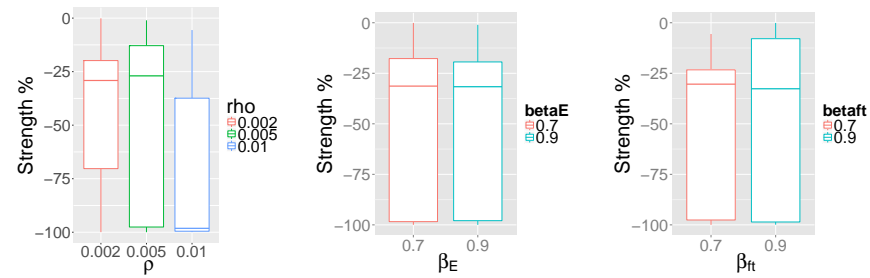

(d) $\rho$

(e) $\beta_{E}$

(f) $\beta_{f t}$

Figure 12: Boxplots for Shear Strength Decrease in terms of each of the six variables; only restrained model

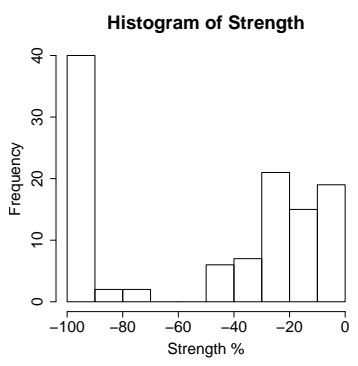

(a) Histogram

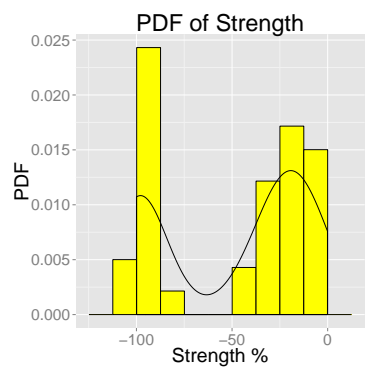

(b) Probability Distribution Function

Figure 13: Histograms for Shear Strength Decrease; only restrained model 